\title{
EFEITO DE DIFERENTES MANEJOS DE FORNECIMENTO PROLONGADO DE COLOSTRO SOBRE OS NIVIEIS DE PROTEÍNA E ALBUMINA SÉRICAS E DESEMPENHO DE BEZERRAS RECÉM-NASCIDAS ${ }^{1}$
}

\author{
C. DANIELE; R. MACHADO NETO; R.S. BARACAT; R. BESSI \\ Departamento de Zoologia - ESALQUSP, C.P. 9 - CEP: 13418-900 - Piracicaba,SP \\ I.U. PACKER \\ Departamento de Zootecnia - ESALQ/USP, C.P. 9 - CEP: 13418-900 - Piracicaba,SP
}

\begin{abstract}
RESUMO: Os níveis séricos de proteína total e albumina e o desempenho de bezerras holandesas foram estudados utilizando-se 24 animais recém-nascidos em um delineamento experimental inteiramente ao acaso em parcelas subdivididas, com três tratamentos à base de leite e colostro suplementar, a saber: tratamento 1 - colostro materno no $1^{\circ}$ dia de vida (idem para tratamentos 2 e 3 ) e 2 litros de leite pela manhã e 2 litros de leite à tarde, do $2^{\circ}$ dia de vida ate o $30^{\circ}$ dia de vida; tratamento 2 - fornecimento de 0,8 litros de leite $+1,2$ litros de colostro pela manhã e 2 litros de leite à tarde, até 30 dias de idade; tratamento 3 - fornecimento de 1,4 litros de leite $+0,6$ litros de colostro pela manhã e igual dieta à tarde, ate 30 dias de idade. Amostras de sangue foram coletadas aos 3, 5, 10, 15, 17, 20, 22, $25,30,40,50$ e 60 dias de vida e analisadas quanto à concentração de proteína total e albumina séricas. Os animais foram pesados ao nascer e aos $5,10,15,20,25,30,40,50$ e 60 dias de idade. Os animais do tratamento 3 (colostro duas vezes/dia) tiveram concentração de proteína total sérica superior $(p \leq 0,05)$ a dos animais do tratamento 1 (leite). $O$ nível sérico de proteína total variou entre idades experimentais $(p \leq 0,0001)$. Houve redução da concentração de proteína total durante o período experimental $\left(r^{2}=0,98\right)$. A albumina sérica não diferiu entre as idades experimentais, havendo porem, diferença entre tratamentos, sendo que os animais do tratamento 2 (colostro uma vez/dia) superaram ( $\leq \leq 0,05$ ) os do tratamento 1 (leite) em relação a está variável. $O$ ganho de peso no período foi maior (p $\leq \mathbf{0 , 0 5}$ ) no tratamento 3 (colostro duas vezes/dia) do que no tratamento 1 (leite). Concluiu-se que o fomecimento de colostro suplementar misturado ao leite duas vezes ao dia proporcionou melhor desempenho das bezerras, evidenciando o seu alto valor nutricional.

Descritores: Albumina sérica, bezerras, colostro suplementar, desempenho, imunidade, proteína total sérica.
\end{abstract}

\section{EFFECT OF DIFFERENT FEEDING PROGRAMS EMPLOYING SUPPLEMENTAL COLOSTRUM ON SERUM TOTAL PROTEIN AND ALBUMIN, AND PERFORMANCE OF NEWBORN CALVES}

\begin{abstract}
The serum total protein and albumin concentrations and the performance under different milk feeding programs were evaluated in twenty-four female Holstein newborn calves, randomly allocated in three treatments. The animals were daily fed milk or supplemental colostrum, in different feeding programs during the first thirty days of life. Blood samples were collected at $3 ; 5 ; 10 ; 15 ; 17 ; 20 ; 22 ; 25 ; 30 ; 40 ; 50$ and 60 days of age and analysed for serum total protein and senum albumin. Animals were weighed at $0 ; 5 ; 10 ; 15 ; 20 ; 25 ; 30 ; 40 ; 50$ and 60 days after birth. In the first sixty days, the serum total protein concentration in treatment 3 (colostrum fed twice a day) was higher ( $p \leq 0.05$ ) than in treatment 1 (milk). The concentration of serum was also different at different ages ( $p \leq$ 0.0001 ). During the experimental period the total protein decreased (equation $r^{2}=0.98$ ). Serum albumin levels were similar at all ages, but different in treatments. Treatment 2 (colostrum fed once a day) levels were higher (p $\leq 0.05$ ) than in treatment 1 for serum albumin. Treatment 3 body weight gain was higher $(p \leq 0.05)$ than in treatment 1 during the experimental period. It was concluded that the best performance was found in calves that received a supplemental colostrum diet twice a day.
\end{abstract}

Key words: Dairy calves, immunity, performance, serum albumin, serum total protein, supplemental colostrum.

\footnotetext{
1 Parte da dissertação de mestrado do $1^{\circ}$ autor apresentada a ESALQ/USP, parcialmente financiada pelo CNPq.
} 


\section{INTRODUÇÃO}

Os ruminantes nascem praticamente sem anticorpos na circulação sanguínea, sendo estes adquiridos sob a forma de imunidade passiva através do colostro materno (PORTER, 1979). Daí a importância do fornecimento do colostro de boa qualidade imediatamente após o nascimento dos bezerros, garantindo baixas taxas de mortalidade e morbidez (RIBEIRO et al., 1983; BRAUN \& TENNANT, 1983).

O padrão de variação dos níveis séricos de imunoglobulinas em bezerros pode ser considerado um reflexo do padrão de variação da proteína total sérica, pois a primeira faz parte da segunda fração (NOCEK et al., 1984), sendo que flutuações podem ser mais facilmente verificadas na concentração de proteína total sérica.

NOCEK et al. (1984), observaram uma correlação positiva entre proteína' total e imunoglobulina $G$ séricas no período de 12 horas a 11 dias após o nascimento, após a ingestão do colostro. Das 12 horas até 4 dias, a correlação apresentou $\mathrm{r}=0,84$, sendo a mais baixa verificada aos 11 dias de vida $(r=0,69)$, indicando que esta relação começa a diminuir com o tempo.

O comportamento dessas variáveis segue um padrão semelhante desde o nascimento do bezerro, quando este apresenta os níveis mais baixos de proteína total, o qual atinge um pico de concentração aos 4 dias de vida, refletindo a absorção de grande quantidade de imunoglobulinas provenientes do colostro e, então, começa a diminuir gradativamente até se estabilizar (TENNANT et al., 1969 ; FAGLIARI et al., 1983; NOCEK et al., 1984).

A queda no nível sérico de proteína total, após o pico de concentração, reflete o catabolismo protéico das imunoglobulinas séricas que foram adquiridas passivamente do colostro materno (TENNANT et al.,1969; BUSH et al., 1971; HUSBAND et al., 1972; RIBEIRO et al., 1983; MACHADO NETO et al., 1986). Da mesma maneira, a estabilização da concentração da proteína total sérica reflete a produção endógena das imunoglobulinas pelo bezerro (HUSBAND et al., 1972).

A albumina representa a maior fração constituinte da proteína total sérica e é a principal responsável pela manutenção da pressão osmótica no soro sanguíneo, podendo a sua concentração variar em consequência da flutuação de outras classes de proteínas séricas (GUYTON, 1978).
Por outro lado, tem sido atribuído papel de proteção local aos anticorpos existentes no colostro fornecido suplementarmente aos bezerros, os quais protegeriam a mucosa intestinal do ataque patogênico pela aderência a mesma, levando a menores incidências de diarréia (SNODGRASS et al., 1980; SAIF et al., 1983; SAIF \& SMITH, 1985; BELLINZONI et al., 1989; CASTRUCCI et $a l ., 1989$; TSUNEMITSU $e t$ al., 1989).

Neste trabalho, procurou-se estudar a ocorrência de variação nos níveis séricos de albumina e sua relação com a variação de proteína total sérica, verificando se perdas de fluídos corporais seriam compensadas pela albumina na tentativa de manter a pressão osmótica do sangue constante. Com o fornecimento do colostro suplementar, procurou-se estudar ainda o desempenho em relação ao ganho de peso corporal dos animais, considerando-se $o$ alto valor nutricional do colostro em relação ao leite (FOLEY \& OTTERBY, 1978; NOCEK et al., 1984), além do efeito de proteção imunológica local deste colostro suplementar (MACHADO NETO et al., 1989), o que reduziria perdas de peso corporal pela diminuição na severidade de diarréia.

\section{MATERIAL E MÉTODOS}

A fase experimental de campo foi realizada na Fazenda Agrindus S.A., município de Descalvado, São Paulo. Foram utilizadas 24 bezerras recém-nascidas da raça Holandesa, as quais foram sendo alocadas ao acaso em três tratamentos, cuja ordem foi sorteada previamente: $\mathrm{T} 1$ (controle) $=$ colostro materno no primeiro dia de vida (idem para os tratamentos 2 e 3) e a partir daí, apenas leite até a desmama, sendo 2 litros pela manhã e 2 litros à tarde; $\mathrm{T} 2=$ fornecimento de 0,8 litros de leite + 1,2 litros de colostro pela manhã e 2 litros de leite à tarde, até 30 dias de idade e $\mathrm{T} 3=$ fornecimento de 1,4 litros de leite $+0,6$ litros de colostro pela manhã e igual dieta à tarde, até $\mathbf{3 0}$ dias de idade. Dois animais do T1 morreram antes do final do experimento, um aos 35 e outro aos 45 dias de idade.

0 leite fornecido aos animais era proveniente das ordenhas de vacas e novilhas da propriedade. $O$ colostro foi armazenado em freezer e consistiu de "pools" provenientes da primeira e segunda ordenhas pós-parto das vacas e novilhas do rebanho. Através do uso de um colostrômetro no campo, foram determinadas as concentrações de imunoglobulinas de cada "pool" (FLEENOR \& STOTT, 1980) podendo-se chegar à quantidade 
média, em gramas, fornecida diariamente $(77.78 \mathrm{~g}$ de Ig/dia) aos animais nos tratamentos com colostro adicional.

Os animais eram mantidos em baias individuais $e$ aleitados artificialmente por mamadeiras plásticas até 90 dias de idade em regime de desmama gradual. $O$ manejo sanitário da propriedade incluiu tratamento veterinário contra tristeza, pneumonia e diarréia, além de vermifugação, descorna e vacinação contra carbúnculo. Havia à disposição dos animais, água, feno e concentrado para bezerros, este último a partir do oitavo dia de vida. Diariamente era trocada a cama das baias e feita a limpeza do piso.

As amostras de sangue foram coletadas da veia jugular dos animais nas seguintes idades pósparto: $3,5,10,15,17,20,22,25,30,40,50$ e 60 dias. $O$ soro separado após centrifugação foi mantido em freezer a $-20^{\circ} \mathrm{C}$ ) até a realização das análises. Os animais foram pesados nas seguintes idades: no nascimento; $5 ; 10 ; 15 ; 20 ; 25 ; 30 ; 40$; 50 e 60 dias de vida.

As amostras de soro foram analisadas quanto à proteína total sérica pelo método de biureto (REINHOLD, 1953), onde $100 \mu \mathrm{l}$ de soro $+4,9 \mathrm{ml}$ de $\mathrm{NaOH}(0,75 \mathrm{~N})+1,0 \mathrm{ml}$ de biureto reativo foram misturados em Vortex, e reagiram por 20 minutos, procedendo-se, então a leitura em espectrofotômetro com comprimento de onda de $545 \mathrm{~nm}$. Através de concentrações padrão de proteína sérica, obtiveram-se curvas padrões e com as leituras foram calculadas as concentrações de proteína total sérica em $\mathrm{g} / \mathrm{dl}$ para as idades experimentais de cada animal.

A albumina sérica foi separada através de eletroforese em fitas de acetato de celulose, onde a diferença de potencial usada no sistema foi de $\mathbf{2 0 0}$ Volts por 20 minutos e o tampão foi barbital sódico a $8,40 \mathrm{~g} / \mathrm{l}$, TRIS + glicina + pirofosfato. Após a separação, as fitas foram imersas em corante Ponceau-S por 10 minutos, lavadas em água $\mathrm{e}$ descoloridas em ácido acético $5 \%$ para leitura em densitômetro, obtendo-se as porcentagens de albumina existentes nas amostras.

$O$ delineamento experimental foi inteiramente casualizado para parcelas sub-divididas, onde os tratamentos foram as parcelas $e$ as idades experimentais as sub-parcelas. Procedeu-se a análise estatística usando-se o programa SAS INSTITUTE (1988), onde os parâmetros séricos foram submetidos à análise da variancia $e$ comparação de médias, quando necessário (TUKEY'S STUDENTIZED). Traçaram-se equações de regressão não linear pelo método DUD para demonstrar o comportamento da proteína total sérica durante o período de 3 a 60 dias de idade.

\section{RESULTADOS E DISCUSSÃO}

Proteína Total Sérica (PT). Os níveis médios de PT sérica são apresentados por tratamento na TABELA 1 e ilustrados na Figura 1.

Os valores máximos de PT sérica encontrados foram: $7,33 \pm 1,20$ para $\mathrm{T} 1 ; 7,82 \pm 1,24$ para T2, ambos aos 3 dias e 8,34 $\pm 1,02 \mathrm{~g} / \mathrm{dl}$ para T3, aos 5 dias de idade. Já os menores valores médios de PT sérica foram $6,12 \pm 0,42$ para $T 1$; $6,69 \pm 0,80$ para $T 2$, ambos aos 30 dias e $6,92 \pm$ $0,52 \mathrm{~g} / \mathrm{dl}$ para $\mathrm{T} 3$, aos $60 \mathrm{dias}$ de vida. Estes valores de PT sérica estão de acordo com aqueles encontrados por MACHADO NETO et al. (1986).

Os níveis de PT sérica variaram entre idades experimentais $(p \leq 0,0001)$ e entre os tratamentos ( $p \leq 0,0321$ ), sendo que a média no T3 (colostro duas vezes/dia) foi superior ( $p \leq$ $0,05)$ à média encontrada no T1 (leite).

A PT sérica apresentou comportamento médio decrescente exponencial conforme a equação: PT $=8,244$. idade ${ }^{-0,055 s}$, sendo a PT dada em $\mathrm{g} / \mathrm{dl}$, onde $r^{2}=0,98$.

O resultado está de acordo com o comportamento da PT sérica observado por outros autores, onde após o pico (cerca de 3 dias de idade), há o declínio, devido ao catabolismo dos anticorpos adquiridos passivamente e a estabilização, refletindo o comportamento das imunoglobulinas (BUSH et al., 1971; HUSBAND et al., 1972; FAGLIARI et al., 1983; MACHADO NETO et al., 1986). O prolongado período de declínio pode refletir uma estabilização mais demorada em virtude da produção endógena inicial de anticorpos ser insipiente (HUSBAND et al., 1972).

Albumina. Os níveis médios de albumina sérica são apresentados na TABELA 2 e ilustrados na Figura 2.

A albumina não variou com a idade dos animais, mantendo sua concentração constante ao longo do período analisado. $O$ valor médio da albumina no T2 (colostro uma vez/dia) foi maior $(p \leq 0,05)$ que no T1 (leite). Este resultado pode refletir o menor nível de PT sérica, também verificado no $\mathrm{T} 1$, já que a albumina representa a maior parte da fração PT sérica. 
Tabela 1 - Concentração média de proteína total sérica (g/d1) nos três tratamentos.

\begin{tabular}{|c|c|c|c|}
\hline \multirow{3}{*}{$\begin{array}{l}\text { Idade } \\
\text { (dias) }\end{array}$} & \multicolumn{3}{|c|}{ Tratamentos } \\
\hline & 1 & 2 & 3 \\
\hline & Média & Média & Média \\
\hline 3 & $7,33 \pm 1,20$ & $7,82 \pm 1,24$ & $8,18 \pm 1,62$ \\
\hline 5 & $7,01 \pm 0,93$ & $7,73 \pm 1,27$ & $8,34 \pm 1,02$ \\
\hline 10 & $6,97 \pm 1,40$ & $7,30 \pm 1,30$ & $7,62 \pm 0,57$ \\
\hline 15 & $6,28 \pm 0,59$ & $6,98 \pm 0,88$ & $7,37 \pm 0,74$ \\
\hline 17 & $6,79 \pm 1,61$ & $6,84 \pm 0,84$ & $7,22 \pm 0,55$ \\
\hline 20 & $6,68 \pm 0,58$ & $7,06 \pm 0,54$ & $7,31 \pm 0,45$ \\
\hline 22 & $6,31 \pm 0,48$ & $7,10 \pm 0,77$ & $7,33 \pm 0,70$ \\
\hline 25 & $6,17 \pm 0,29$ & $6,91 \pm 0,82$ & $7,34 \pm 0,42$ \\
\hline 30 & $6,12 \pm 0,42$ & $6,69 \pm 0,80$ & $7,41 \pm 0,49$ \\
\hline 40 & $6,19 \pm 0,48$ & $6,89 \pm 0,93$ & $6,95 \pm 0,48$ \\
\hline 50 & $6,26 \pm 0,48$ & $6,81 \pm 0,76$ & $6,93 \pm 0,41$ \\
\hline 60 & $6,36 \pm 0,52$ & $7,35 \pm 0,84$ & $6,92 \pm 0,52$ \\
\hline Média & $6,54 \pm 0,38$ & $7,12 \pm 0,34$ & $7,41 \pm 0,43$ \\
\hline
\end{tabular}

OBS: $\quad$ TRAT $1=$ leite; TRAT $2=$ Colostro 1 vez ao dia; TRAT $3=$ Colostro 2 vezes ao dia; DP $=$ desvio padrão.

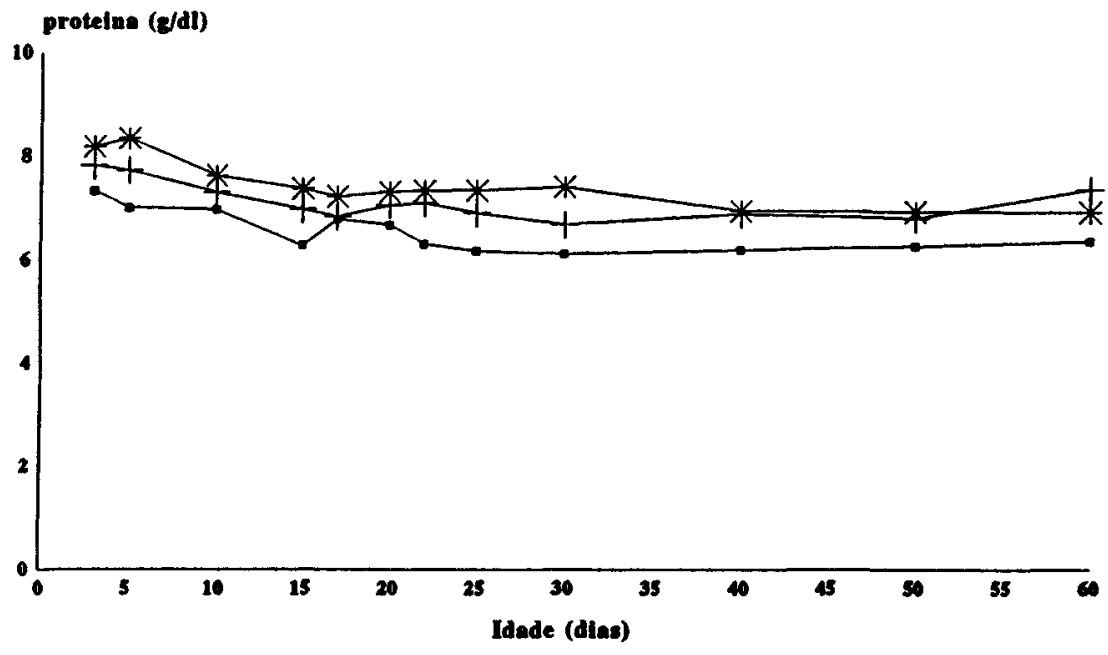

- Trat 1 +Trat 2 * Trat 3

Figura 1 - Concentração média de proteína total sérica $(\mathrm{g} / \mathrm{dl})$ nos tratamentos. 
Tabela 2 - Concentração média de albumina sérica $(\mathrm{g} / \mathrm{d} 1)$ nos três tratamentos.

\begin{tabular}{|c|c|c|c|}
\hline \multirow{3}{*}{ Idade } & \multicolumn{3}{|c|}{ Tratamentos } \\
\hline & 1 & 2 & 3 \\
\hline & Média & Média & Média \\
\hline 3 & $2,96 \pm 0,35$ & $3,28 \pm 0,66$ & $3,01 \pm 0,25$ \\
\hline 5 & $2,87 \pm 0,45$ & $3,02 \pm 0,52$ & $3,05 \pm 0,72$ \\
\hline 10 & $3,12 \pm 0,55$ & $3,21 \pm 0,89$ & $3,07 \pm 0,46$ \\
\hline 15 & $3,16 \pm 0,65$ & $3,38 \pm 0,53$ & $2,91 \pm 0,45$ \\
\hline 17 & $3,13 \pm 0,45$ & $3,56 \pm 0,90$ & $2,89 \pm 0,38$ \\
\hline 20 & $3,38 \pm 0,17$ & $3,37 \pm 0,71$ & $3,13 \pm 0,58$ \\
\hline 22 & $3,15 \pm 0,33$ & $3,24 \pm 0,42$ & $3,01 \pm 0,54$ \\
\hline 25 & $3,14 \pm 0,52$ & $3,44 \pm 0,39$ & $3,47 \pm 0,26$ \\
\hline 30 & $2,90 \pm 0,39$ & $3,45 \pm 0,67$ & $3,92 \pm 0,63$ \\
\hline 40 & $2,95 \pm 0,63$ & $3,57 \pm 0,67$ & $3,75 \pm 0,62$ \\
\hline 50 & $3,11 \pm 0,72$ & $3,31 \pm 0,37$ & $3,22 \pm 0,36$ \\
\hline 60 & $2,93 \pm 0,16$ & $3,19 \pm 0,39$ & $3,19 \pm 0,69$ \\
\hline Média & $3,07 \pm 0,14$ & $3,33 \pm 0,15$ & $3,22 \pm 0,31$ \\
\hline
\end{tabular}

OBS: $\quad$ TRAT $1=$ leite; TRAT $2=$ Colostro 1 vez ao dia; TRAT $3=$ Colostro 2 vezes ao dia; DP = desvio padrão.

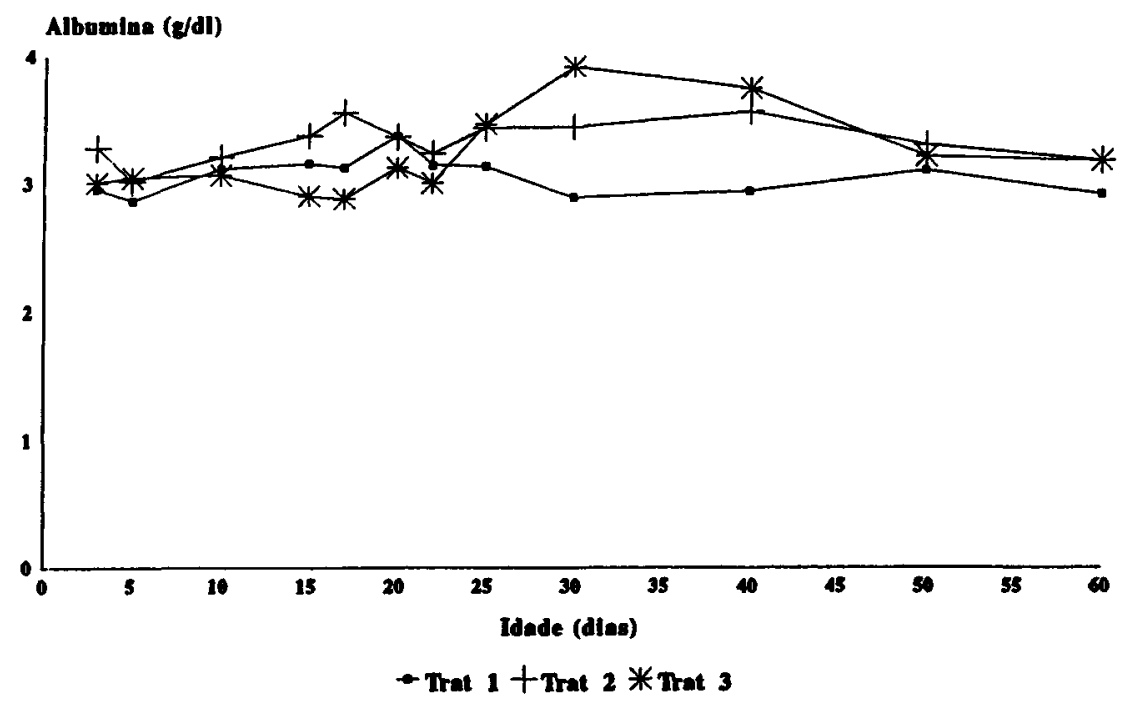

Figura 2 - Concentração média de albumina sérica $(g / d l)$ nos tratamentos. 
Tabela 3 - Pesos médios $(\mathrm{kg})$ por tratamento, no período de 1 a 60 dias de idade.

\begin{tabular}{|c|c|c|c|}
\hline \multirow{3}{*}{$\begin{array}{l}\text { Idade } \\
\text { (dias) }\end{array}$} & \multicolumn{3}{|c|}{ Tratamentos } \\
\hline & 1 & 2 & 3 \\
\hline & Média & Média & Média \\
\hline 1 & $38,4 \pm 5,8$ & $38,0 \pm 6,6$ & $37,6 \pm 4,8$ \\
\hline 5 & $38,8 \pm 6,4$ & $40,1 \pm 5,3$ & $39,3 \pm 4,6$ \\
\hline 10 & $41,2 \pm 5,7$ & $41,7 \pm 5,5$ & $41,8 \pm 4,5$ \\
\hline 15 & $40,4 \pm 4,6$ & $42,4 \pm 5,4$ & $44,2 \pm 4,3$ \\
\hline 20 & $42,7 \pm 4,6$ & $43,9 \pm 4,9$ & $44,9 \pm 3,5$ \\
\hline 25 & $44,5 \pm 5,5$ & $45,6 \pm 5,6$ & $46,5 \pm 4,7$ \\
\hline 30 & $45,2 \pm 4,4$ & $48,7 \pm 4,8$ & $48,7 \pm 4,9$ \\
\hline 40 & $48,1 \pm 3,1^{1}$ & $52,6 \pm 7,2^{3}$ & $50,7 \pm 3,6^{3}$ \\
\hline 50 & $53,6 \pm 6,7^{2}$ & $58,1 \pm 7,9$ & $59,2 \pm 6,3$ \\
\hline 60 & $60,2 \pm 8,9^{2 *}$ & $64,7 \pm 8,4$ & $70,7 \pm 7,0 *$ \\
\hline
\end{tabular}

OBS: $\quad$ TRAT $1=$ leite; TRAT $2=$ Colostro 1 vez ao dia; TRAT $3=$ Colostro 2 vezes ao dia; $\mathbf{~} n=$ 7 (morte); ${ }^{2} n=6$ (morte); ${ }^{3} n=7$ (os animais $n^{\circ} 1$ deste tratamento não foram pesados no $40^{\circ}$ dia); $*$ alfa $=5 \%$

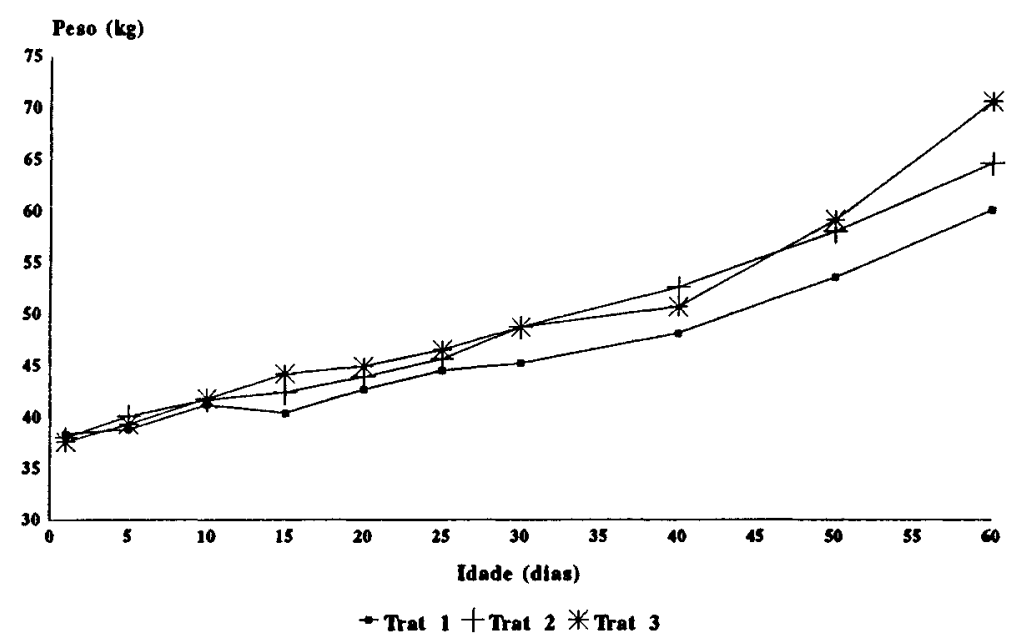

Figura 3 - Pesos médios observados nos tratamentos durante 60 dias de idade.

Não foi possível relacionar o comportamento da albumina sérica aos mecanismos de manutenção da pressão osmótica sanguínea durante os processos de perdas de fluidos corporais devido à diarréia, embora sua constância possa evidenciar o equilíbrio frente a flutuações nos níveis de anticorpos ou outras proteínas séricas.

Peso Corporal. Os dados referentes às pesagens dos animais estão apresentados na TABELA 3 e ilustrados na Figura 3. 
Tabela 4 - Ganho de peso (kg) total dos animais em cada tratamento, de 1 a 60 dias de idade

\begin{tabular}{cccc}
\hline Animais & Trat 1 (leite) & Trat 2 (col. 1v) & Trat 3 (col. 2v) \\
\hline 1 & 22,5 & 31,5 & 35,0 \\
2 & 26,5 & 29,5 & 32,5 \\
3 & -1 & 24,5 & 39,5 \\
4 & -1 & 19,0 & 28,0 \\
5 & 18,0 & 24,5 & 41,0 \\
6 & 17,0 & 26,0 & 27,0 \\
7 & 16,0 & 26,0 & 28,5 \\
8 & 35,0 & 32,5 & 33,5 \\
Média & 22,50 & 26,69 & 33,12 \\
DP (t) & 7,28 & 4,38 & 5,23 \\
\hline
\end{tabular}

OBS: $\quad 1=$ Amostras perdidas em função da morte destes animais antes dos 60 dias de idade.

DP $=$ desvio padrão.

Os pesos médios iniciais foram semelhantes nos três tratamentos, não influindo no ganho de peso total, enquanto os pesos médios finais, bem como o ganho de peso no período experimental total, diferiram entre tratamentos. As bezerras do $\mathrm{T} 3$ ganharam mais peso que as do $\mathrm{T} 1$ (TABELA 4). No T3, onde as bezerras receberam colostro adicional 2 vezes ao dia, o maior ganho de peso pode ter sido em funçãa do colostro ser uma fonte alimentar mais rica em sólidos totais comparado ao leite (T1), de acordo com FOLEY \& OTTERBY (1978) e NOCEK et al. (1984).

As bezerras do T3, também tiveram menor severidade de diarréia, refletindo possivelmente uma melhor proteção local dos anticorpos adicionais distribuídos uniforme e constantemente no trato digestivo, levando à menor perda de peso e maior aproveitamento dos nutrientes do colostro, com melhor desempenho para estes animais.

$O$ nível inicial de PT, que reflete a aquisição de imunoglobulinas passivas, não interferiu no ganho de peso final, o que está de acordo com NOCEK et al. (1984) e EDWARDS et al. (1982), onde afirmam que níveis iniciais altos de anticorpos passivos não afetam o ganho de peso corporal.

\section{CONCLUSÕES}

O fornecimento duas vezes ao dia, de colostro suplementar misturado ao leite mostrou-se prática eficiente por proporcionar maior proteção local contínua no lúmen intestinal, bem como maximizando o desempenho dos animais.

\section{REFERENCIAS BIBLIOGRÁFICAS}

BELLINZONI, R.C.; BLACKHALL, J.; BARD, N. Efficacy of an inactivated oil-adjuvanted rotavirus vaccine in the control of calf diarthoea in beef herds in Argentina. Vaccine, Surrey, v.7, p.263-268, Jun. 1989.

BRAUN, R.K.; TENNANT, B.C. The relationship of serum gammaglobulin levels of assembled neonatal calves to mortality caused by enteric disorders. Agripractice. Santa Barbara. v.4, n.5, p.14-24, May 1983.

BUSH, L.J.; AGHILERA, M.A.; ADAMS, G.D. Absorption of colostral immunoglobulins by newborn dairy calves. Journal of Dairy Science, Champaign, v.54, n.10, p.1547-1549, Oct. 1971.

CASTRUCCI, C.; FRIGERI, F.; FERRARI, M. Further studies on passive immunization of newborn calves against rotaviral infection. Comparative Immunology, Microbiology and Infections Diseases, Great Britain, v.12, n.3, p.71-76, Oct. 1989.

EDWARDS, S.A.; BROOM, D.M.; COLLIS, S.C. Factors effecting levels of passive immunity in dairy calves. British Veterinary Journal, London, v.138, n.3, p.233-240, May/June 1982. 
FAGLIARI, J.J.; FERREIRA NETO, J.M.; LUCAS, A Proteína total e fracionamento eletroforético do soro de bezerros guzerá passivamente imunizados contra paratifo. Arquivo Brasileiro de Medicina Veterinária e Zootecnia, Belo Horizonte, v.35, n.3, p.317-332, June 1983.

FLEENOR, W.A.; STOTT, G.H. Hydrometer test for estimation of immunoglobulin concentration in bovine colostrum. Journal of Dairy Science, Champaign, v.63, n.6, p.973-977, June 1980.

FOLEY, J.A.; OTTERBY, D.E. Availability, storage, treatment, composition and feeding value of surplus colostrum: a review. Joumal of Dairy Science, Champaign. v.61, n.8, p.1033-1060, Aug. 1978.

GUYTON, A.C. Digestão e absorção no trato gastrointestinal e distúrbios gastrointestinais. In: SAUNDERS, W.B., (Ed.) Fisiologia básica. Rio de Janeiro: Interamericana, 1978, cap.44, p.470-480.

HUSBAND, A.J.; BRANDON, M.R.; LASCELLES, A.K. Absorption and endogenous production of immunoglobulins in calves. Australian Journal of Experimental Biology and Medical Science, Adelaide, v.50, p.491-498, Sep. 1972.

MACHADO NETO, R.; PACKER, I.U.; SUSIN, I. Concentração de imunoglobulina sérica, peso corporal e diarréia em bezerros da raça holandesa aleitados com diferentes dietas. Turrialba, Costa Rica, v.39, n.1, p.51-55, Mar. 1989

MACHADO NETO, R.; PACKER, I.U.; SUSIN, I. Proteína total sérica em bezerros da raça holandesa submetidos a diferentes regimes de aleitamento. Anais da Escola Superior de Agricultura "Luiz de Queiroz", Piracicaba, v.43, n.1, p.265-283, 1986.

NOCEK, J.E.; BRAUND, D.G.; WARNER, R.G. Influence of neonatal colostrum administration, immunoglobulin, and continued feeding of colostrum on calf gain, health, and serum protein. Journal of Dairy Science, Champaign, v.67, n.2, p.319-333, Feb. 1984

PORTER, P. Structural and functional characteristics of immunoglobulins of the common domestic species. Advances in Veterinary Science and Comparative Medicine, New York, v.23, p.1-21, Mar. 1979.
REINHOLD, J.G. Total protein, albumin and globulin. In: REINER, M.(Ed.) Standard methods of clinical chemistry. New York: Academic Press, 1953. v.1, p.88.

RIBEIRO, M.F.B; BELÉM, P.A.D.; PARARROYO, J.H. Hipogamaglobulinemia em bezerros. Arquivo Brasileiro de Medicina Veterinaria e Zootecnia, Belo Horizonte. v.35, n.4, p.537-546, Aug. 1983.

SAIF, L.J.; SMTTH, L. Enteric viral infections of calves and immunity. Journal of Dairy Science, Champaign, v.68, n.1, p.206-228, Jan. 1985 .

SAIF, L.J.; REDMAN, D.R.; SMITH, K.L. Passive immunity to bovine rotavirus in newborn calves fed colostrum supplements from immunized or nonimmunized cows. Infection and Immunity, Washington, v.41, n.3, p.1118-1131, Sep. 1983.

SAS INSTITUTE. User's guide. Carry, 1988. 2v.

SNODGRASS, D.R.; FAHEY, K.J.; WELLS, P.W. Passive immunity in calf rotavirus infection: maternal vaccination increases and prolongs immunoglobulins G1 antibody secretion in milk. Infection and Immunity, Washington, v.28, n.2, p.344-349, Feb. 1980

TENNANT, B.; HARROLD, D.; GUERRA, M.R. Neonatal alterations in serum gammaglobulin levels of Jersey and Holstein-Friesian calves. American Journal of Veterinary Research, Chicago, v.51, n.2, p.345-354, Sep. 1969

TSUNEMITSU, H.; SHIMIZU, M.; HIRAI, T. Protection against bovine rotavirus in newborn calves by continuos feeding of immune colostrum. Japan Journal of Veterinaty Science, Tokio, v.51, n.2, p.300-308, Feb. 1989.

Enviado para publicação em 20.01 .94

Aceito para publicação em 28.03.94 